\title{
INTRA-URBAN HEAT ISLAND DETECTION AND TREND CHARACTERIZATION IN METRO MANILA USING SURFACE TEMPERATURES DERIVED FROM MULTI-TEMPORAL LANDSAT DATA
}

\author{
K. P. Landicho', *, A.C. Blanco ${ }^{1,2}$ \\ ${ }^{1}$ Training Center for Applied Geodesy and Photogrammetry, University of the Philippines Diliman, Quezon City 1101, \\ Philippines \\ ${ }^{2}$ Department of Geodetic Engineering, University of the Philippines Diliman, Quezon City 1101, Philippines \\ kclandicho1@up.edu.ph, acblanco@up.edu.ph
}

\section{Commission IV}

KEY WORDS: Urbanization, Local Moran's I, Google Earth Engine, Emissivity, Hotspot, Coldspot, Histogram, Trendlines

\begin{abstract}
:
Unprecedented urbanization in Metro Manila has led to the proliferation of the urban heat island (UHI) effect. This is characterized by a prominent difference in the temperatures of the urban and its surrounding rural and less urbanized areas. Temperature differences occur within these UHI's indicating the existence of intra-urban heat islands (IUHI). UHI's and IUHI's are welldocumented indicators of urban environmental degradation and therefore puts the population of Metro Manila at risk. In anticipation of these effects, their detection and the characterization of their behaviour through time can contribute to proper urban planning thus mitigating harmful effects. Google Earth Engine was used to retrieve land surface temperatures (LST) from Landsat data from 1997 to 2019 using emissivity estimation. The Local Moran's I statistic was then used to identify cluster and outlier types (COT). A histogram with 10 bins representing the net COT frequencies per barangay was then used to identify IUHI's. Annual temperature measurements and COT areas were plotted against time and based on linear-fit trend lines they characterize the study area as to having an annual increase in temperature of roughly $0.18^{\circ} \mathrm{C}$ and hotspot area extent of around $0.03 \mathrm{~km}^{2}$, and a decrease in coldspot area extent around $0.01 \mathrm{~km}^{2}$. Hotspots were found to be frequent in the cities of Caloocan, Manila, Pasay, and Quezon while coldspots were found to be frequent in the cities of Caloocan, Las Piñas, Malabon, Navotas, and Valenzuela. In conclusion, IUHI's were detected with statistical basis, both spatially and temporally.
\end{abstract}

\section{INTRODUCTION}

The Philippines is an urbanized nation based on a report by the Asian Development Bank (ADB) in 2014 which also said that close to 50 percent of the Philippine population live in the country's urban areas. This urbanization along with the growth of the urban population, entails continuous conversion of natural land cover surfaces into impervious surfaces ultimately leading to higher land surface temperatures (LST) as observed in numerous studies. It is also known that urbanization has caused widespread climatic, ecological, and health-related problems (Bartkowiak and Osinska-Skotak, 2018; Jeevalakshmi et al., 2017). One of the most familiar effects of urbanization is the Urban Heat Island (UHI) phenomenon (Pahlavani et al., 2017). UHI was first described by Howard in 1818 and is characterized as urban areas having LST's higher than its periphery of less or non-urbanized areas (Howard, 1818; Xian and Crane, 2005 as cited in Pahlavani et al., 2017). However, significant temperature differences exist within city limits or within the extents of these UHI's. This has led to the belief of the existence of Intra-Urban Heat Islands (IUHI). Clearly, this puts the Philippine population health at risk of severe heat stress as well as foreseeable increased energy demand among many other adaptive measures. To address this problem, urban planning in the country should consider detecting Urban Heat Islands (UHI), particularly IntraUrban Heat Islands (IUHI) in order to mitigate its development, expansion, and harmful effects.

Bartkowiak and Osinska-Skotak (2018) claimed that the use of satellite imagery as in this study, allows the possibility of assessing climatological phenomena as in this case, spatial and temporal distribution of LST. Google Earth Engine (GEE) allows planetary-scale analysis of geospatial data (Gorelick et al., 2017). This study aims to detect IUHI's by defining temperature thresholds with respect to spatial reference as in Martin, Baudouin and Gachon (2015) and their development and persistence through time in Metro Manila from the years 1997 to 2019.

Integrated remote sensing and Geographic Information Systems (GIS) techniques were used to achieve the results of this study. LST data were retrieved from Landsat 5 Thematic Mapper (TM) and Landsat 8 Operational Land Imager/Thermal Infrared Sensor (OLI/TIRS) using GEE further detailed in the succeeding parts of the paper. Statistically significant clusters were identified using GeoDa and a database of LST and cluster identification summarized in 100-meter by 100-meter grid cells covering the study area, was done in ArcGIS. Other necessary processing to identify IUHI's were also done in ArcGIS.

\section{STUDY AREA}

The Philippines is a tropical country routinely experiencing high climatic temperatures often in conjunction with high humidity levels. Metro Manila is composed of 16 cities namely: Caloocan, Las Piñas, Malabon, Manila, Mandaluyong, Marikina, Muntinlupa, Navotas, Parañaque, Pasay, Pasig, San Juan, Taguig, and Valenzuela with the inclusion of the municipality of Pateros. The region is claimed to be the center of culture, economy, education and government in the Philippines with an area of 619.57 square kilometers and a population of $12,877,253$ as of 2015. Metro Manila has a tropical wet and dry climate bordering on a tropical monsoon climate. The country's proximity to the equator causes temperature to range from $20^{\circ} \mathrm{C}$ 
to $38^{\circ} \mathrm{C}$. Dry seasons last from January to April while the wet seasons from May to December (National Nutrition Council, 2015).

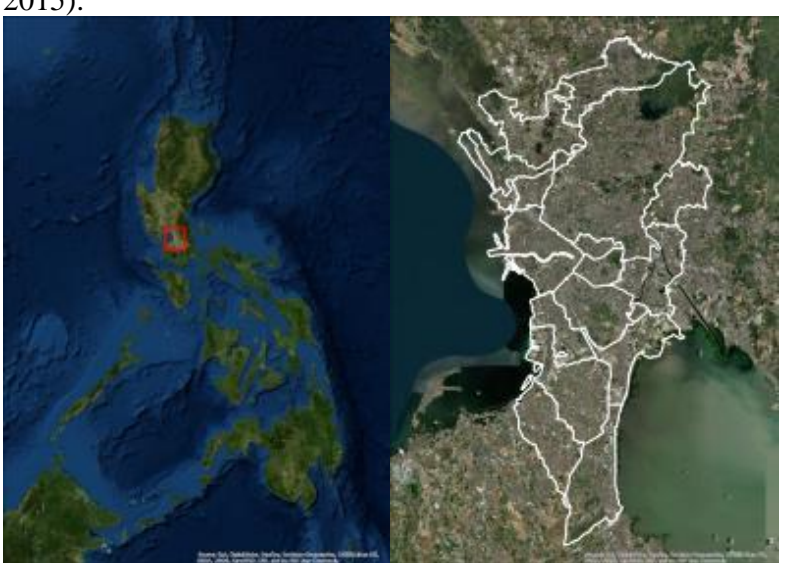

Figure 1. Map of study area (a) Philippines, (b) Metro Manila Source: Esri, DigitalGlobe, GeoEye, EarthstarGeographics, CNES/Airbus DS, USDA, USGS, AeroGRID, IGN, and the GIS User community.

\section{MATERIAL AND METHODS}

\subsection{Data}

The data that were used in this study are summarized in Table 1 . Satellite images, particularly the thermal bands from Landsat 5 TM, and Landsat 8 OLI/TIRS covering the time period 1997 to 2019 were used in the study. A 100-meter by 100 -meter grid was created with the same extent as the regional boundary of Metro Manila and immediate bounding municipalities to address the well-known edge effects in spatial statistics. Corresponding point labels were created simultaneously with the use of the "Create Fishnet" tool in ArcGIS.

\begin{tabular}{|c|c|c|}
\hline Data & $\begin{array}{c}\text { Spatial } \\
\text { Resolution }\end{array}$ & Source \\
\hline Landsat 5 TM & 100 resampled & Google Earth \\
\hline$(1997-2011)$ & to $30 \mathrm{~m}$ & Engine \\
\hline Landsat 8 & 100 resampled & Google Earth \\
\hline $\begin{array}{l}\text { OLI/TIRS (2013- } \\
\text { 2019) }\end{array}$ & to $30 \mathrm{~m}$ & Engine \\
\hline NCR Boundary & - & PhilGIS.org \\
\hline Grid (Feature) & $100 \mathrm{~m}$ & $\begin{array}{l}\text { NCR extent, } \\
\text { snapped to Landsat } \\
\text { pixels }\end{array}$ \\
\hline $\begin{array}{l}\text { Grid Label } \\
\text { (Point) }\end{array}$ & - & $\begin{array}{l}\text { Created along with } \\
\text { Grid }\end{array}$ \\
\hline
\end{tabular}

Table 1. Data summary.

\subsection{Land Surface Temperature Retrieval}

LST data were retrieved from Landsat $5 \mathrm{TM}$ and Landsat 8 OLI/TIRS satellite imagery. The methodology used for LST retrieval is from Jeevalakshmi et al. (2017) which used emissivity estimation. The general workflow of the LST retrieval is shown on Figure 2 and is further elaborated in the following sections. After retrieving the LST of the two decade-worth of data (171 images for Landsat 5, 110 images for Landsat 8) they were then grouped and then reduced into annual maxes in Google Earth Engine using the ee.Reducer.max() function. This was done to mask out unlikely low LST values from clouds and other atmospheric effects. The reduced images were then inspected for prevalence of such unlikely low LST values for exclusion. Such prevalence signifies that reducing the images into annual maximum values was not enough to mask out or at least minimize cloud cover or atmospheric effects for that particular year. The result is a collection of annual maximum LST values for the study area.

Jeevalakshmi et al.'s (2017) methodology was originally for Landsat 8 OLI/TIRS data only. It was adapted for application to Landsat 5 TM data in this study. For Landsat 8, Band 10 TIRS 1 was used since it yields more accurate results (Yu et al., 2014 as cited in Bernales et al., 2016).

\subsubsection{Top-of-Atmosphere Radiance}

Equation 1 was used to convert Band 10's digital number (DN) values into top of the atmosphere radiance (ToA Radiance $-\mathrm{L}_{\lambda}$ ):

$$
\mathrm{L}_{\lambda}=\frac{(\text { Lmax }- \text { Lmin }) * Q c a l}{(\text { Qcalmax }-Q \text { calmin })}+\mathrm{Lmin}-\mathrm{Oi}
$$

Where $\quad$ Lmax $=$ maximum radiance $\left(W^{-2} s r^{-1} \mu m^{-1}\right)$

Lmin $=$ minimum radiance $\left(\mathrm{Wm}^{-2} s r^{-1} \mu m^{-1}\right)$

$\mathrm{Qcal}=\mathrm{DN}$ value of pixel

Qcalmax $=$ maximum $\mathrm{DN}$ value of pixels

Oi $=$ correction value for the thermal band (Band 5 for Landsat 5 TM, Band 10 for Landsat 8 OLI/TIRS)

\subsubsection{Brightness Temperature}

The computed ToA Radiance, the thermal band data should then be converted to Brightness Temperature (BT) using the thermal constants (K1 and K2) indicated in the satellite images' metadata and the following equation:

$$
\mathrm{BT}=\frac{K 2}{\ln \left(\frac{K 1}{L \lambda}\right)}-273.15
$$

Where $\mathrm{K} 1$ and $\mathrm{K} 2$ are the satellite images' thermal constants indicated in their metadata and $\mathrm{L}_{\lambda}$ is the computed ToA Radiance. The addition of an absolute zero (-273.15) allows the direct conversion to degrees Celsius.

\subsubsection{Normalized Difference Vegetation Index}

The computation of the Normalized Difference Vegetation Index (NDVI) is necessary for a general differentiation of the land cover types of the study area and is given by the following equation (Jeevalakshmi et al., 2017):

$$
\mathrm{NDVI}=\frac{(N I R-R e d)}{(N I R+R e d)}
$$

Where NIR = reflectance value of the near infrared band Red $=$ reflectance value of the red band

\subsubsection{Proportional Vegetation}

Using the NDVI, the proportional vegetation (Pv) layer can be calculated. This gives the estimation of the land cover type from which the land surface emissivity (LSE) can be computed from (Jeevalakshmi et al., 2017). The Pv layer can be computed using the following equation:

$$
\mathrm{P}_{\mathrm{v}}=\left(\frac{N D V I-N D V I s}{N D V I v-N D V I S}\right)^{2}
$$

Where $\quad$ NDVI $=$ NDVI value at a certain pixel $\mathrm{NDVI}_{\mathrm{v}}=$ NDVI value for vegetation $(0.5$ default; 0.8 for highly vegetated areas)

$\mathrm{NDVI}_{\mathrm{s}}=\mathrm{NDVI}$ value for soils $(0.2)$ 


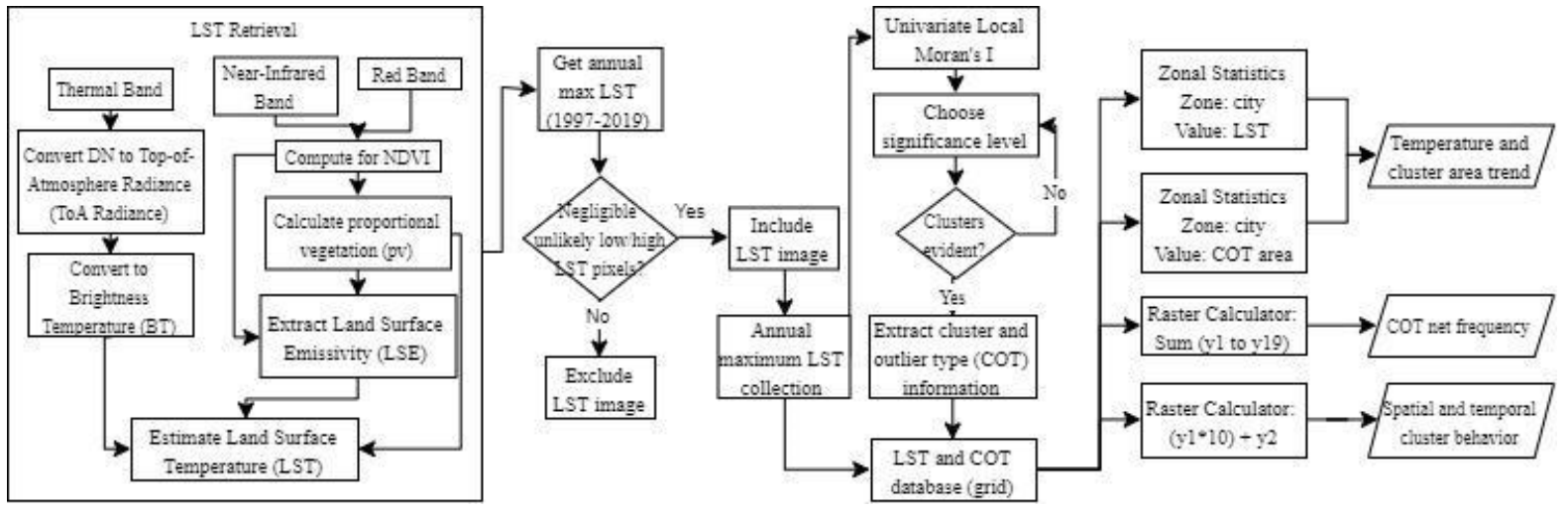

Figure 2. Process workflow for detecting Intra-Urban Heat Islands (IUHIs).

\subsubsection{Land Surface Emissivity}

The Land Surface Emissivity can then be computed using the following equation (Sobrino et al., 2004 as cited in Jeevalakshmi et al., 2017):

$$
\varepsilon_{\lambda}=\varepsilon_{\mathrm{v} \lambda} \mathrm{Pv}+\varepsilon_{\mathrm{s} \lambda}(1-\mathrm{Pv})+\mathrm{C}_{\lambda}
$$

Where $\varepsilon_{v}$ and $\varepsilon_{s}$ are the vegetation and soil emissivities respectively, and $\mathrm{C}$ is the surface roughness taken as a constant value of 0.005 (Jeevalakshmi et al., 2017). The emissivity is then estimated using the NDVI threshold method:

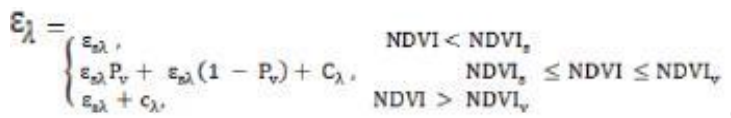

\subsubsection{Land Surface Temperature}

The LST can now be estimated using the following equation (Stathopoulou \& Cartalis, 2007):

$$
\mathrm{T}_{\mathrm{S}}=\frac{B T}{\left\{1+\left[\left(\frac{\lambda B T}{\rho}\right) \ln \varepsilon \lambda\right]\right\}}
$$

Where, Ts is the LST in Celsius $\left({ }^{\circ} \mathrm{C}\right), \mathrm{BT}$ is at-sensor BT also in Celsius, $\lambda$ is the average wavelength of the thermal band, $\varepsilon \lambda$ is the emissivity calculated from equation 6 and $\rho$ is $\left(\mathrm{h} \times \frac{c}{\sigma}\right)$ which is equal to $1.438 \times 10^{-2} \mathrm{mK}$ in which $\sigma$ is the Boltzmann constant $\left(1.38 \times 10^{-23} \mathrm{~J} / \mathrm{K}\right), h$ is Planck's constant $\left(6.626 \times 10^{-34}\right)$ and $c$ is the velocity of light $\left(3 \times 10^{8} \mathrm{~m} / \mathrm{s}\right)$.

\subsection{Intra-Urban Heat Island Detection}

Annual maximum LST values were extracted into the grid point labels. These grid point labels are the centroids of the grid created using the Create Fishnet tool in ArcGIS. LST values from the grid point labels were then joined to the grid cells resulting to a database of annual maximum LST values that match the extent of NCR. A weights matrix file parameter was created using Queen contiguity with a value of 1 . This signifies that for a cell, its immediate adjacent neighbour cells affect it. Each field in this database then served as an input to the univariate Local Moran's I function in GeoDa. This produced Cluster and Outlier Type (COT) maps per year in the study period. The significance filter was set to $\alpha=0.001$ for all years. Output annual COT classifications were then included in the existing LST database. Identified "High-High" clusters were regarded as hotspots and "Low-Low" clusters as coldspots.
Hotspots were assigned a value of 1 , while coldspots were assigned a value of -1 . Using the raster calculator, the total sum of these annual COT classifications was taken to create the net frequency of the COT occurrence for the study area for the study period 1997 to 2019. The number of cells per output class (38) were graphed to provide a broad idea of the COT distribution in the study area. To arrive at definitive areal identifications, barangay (village) zonal means were used to summarize the net frequency scores. A histogram with ten bins representing the net COT frequencies was used to identify IUHI's. The bin representing the barangays with the highest net COT frequencies were regarded as the IUHI's.

\subsubsection{Local Anselin Moran's I}

The Local Moran statistic identifies local clusters and local spatial outliers (Anselin, 1995). This statistic takes the form:

$$
\mathrm{c} \cdot \mathrm{Z}_{\mathrm{i}} \Sigma_{\mathrm{j}} \mathrm{W}_{\mathrm{ij}} \mathrm{Z}_{\mathrm{j}}
$$

Where, $\mathrm{z}$ denotes the deviation from the mean, and $c$ denotes a scalar value that is the same for all locations obtained by means of conditional permutation method, where, in turn, each $\mathrm{zi}$ is held fixed, and the remaining z-values are randomly permuted to yield a reference distribution for the statistic (Anselin, 1995).

\subsection{Trend Characterization}

With the use of the histogram's top and bottom bins, respective barangays classified as frequent hotspots and coldspots were also identified. This histogram groups values into ranges and taller bins indicate that more data fall in that range. It also shows the spread of the data.

Cluster type change was also mapped. Succeeding years were paired (y1 and y2) and corresponding COT classification change from y1 to y2 was mapped. Existing COT classifications were "HH" for high-high, "LL" for low-low clusters and blank for neither. These were reclassified into 2's, 1', and 0's respectively. Using the raster calculator, $\mathrm{y} 1$ was multiplied by 10 and then the y2 raster is added. This results to a two-digit number whose tens place value digit represents the initial condition (y1) and whose ones place value digit represents the new condition (y2). Nine different cluster type changes referred to as "behaviors" were identified: (1) Neutral (no change)-00, (2) Neutral to Coldspot01, (3) Neutral to Hotspot-02, (4) Coldspot to Neutral-10, (5) Coldspot (no change)-11, (6) Coldspot to Hotspot-12, (7) Hotspot to Neutral-20, (8) Hotspot to Coldspot-21, and (9) Hotspot (no change)-22. 
City zonal means of LST, hotspot, and coldspot area percentages (cluster area divided by city area) were also plotted against time to provide a broad idea of the surface temperature trends and the spatial and temporal behavior of the clusters.

\section{RESULTS AND DISCUSSION}

\subsection{Intra-Urban Heat Island Detection}

Different areal units were utilized to investigate and detect IUHI's in the study area. The first one was with the use of 100meter by 100-meter grid cells. Figure 3 shows a graph summarizing the count per output grid cell (pixel) value in the net COT frequency map in raster format (Figure 5.a). On one hand, 1,411 100-meter grid cells were identified to be occurring as coldspots for a total of 19 times out of the 19-year study period. On the other hand, 2 grid cells were identified to be occurring as hotspots a total of 18 times. Noticeably, grid cells with value 1 were found to be the dominant class in the output (8,344 grid cells). The output net frequency ranges from -19 to 18 (coldspots: -19 to -1 ; hotspots: 1 to 18 ) wherein the magnitudes represent the frequency of occurrence of the respective cluster type. With the use of a different areal unit of analysis - city boundaries, average frequency values were taken. A histogram of 10 bins representative of the classes of the output values of the city zonal means were utilized to identify the IUHI's (frequent hotspots) as well as anti-IUHI's (frequent coldspots). Based on the histogram graph (Figure 4), a total of 26 barangays were identified as IUHI's (Figure 6) and 12 as antiIUHI's (Figure 7). Barangays identified as IUHI's are mainly from Caloocan City, Manila, Pasay City, and Quezon City while those identified as anti-IUHI's are from Caloocan City, Las Piñas, Malabon, Navotas, and Valenzuela. The reported mean frequency of the top-tier bin in the histogram ranges from 10.97 to 14.2 while for the bottom-tier bin it was -18.08 to -14.85 . It should be noted however that the use of zonal statistics leads to some loss of spatial detail about the data.

The identified IUHI's as shown in Figure 6 show a common characteristic, its form is of the built environment (referring to man-made structures that are the settings for various human activity-residence, work, recreate). This is expected for barangays in NCR given that it is the center for culture, economy and education as previously mentioned, and it's the most densely populated region of the Philippines $\left(42,857\right.$ people per $\left.\mathrm{km}^{2}\right)$ based on the 2015 census data from the Philippine Statistics Authority. The built environment is a key component of the city but characterizing that of Metro Manila's is problematic. The lack of public spaces such as parks and plazas further exemplified by the existence of contradicting land uses can be traced to the poor urban planning issue in the region which has been made an economic and political issue rather than an environmental and health-concerning topic (Mojarro, 2017). These detected IUHI's should serve as basis as to where local government units and corresponding planning offices can intervene in the face of the worsening temperature conditions. This is due to the built environment playing a huge role in addressing global and local challenges including climate change among many other as according to the United Nations Environment Programme.

The detected anti-IUHI's are mainly the barangays with an evident presence of either water bodies and/or vegetation. Figure 7.a show the barangays from Navotas, Malabon, and Valenzuela. Figure 7.b shows the barangays in Caloocan City in the proximity of the La Mesa watershed. Lastly, Figure 7.c shows the Las Piñas-Parañaque Critical Habitat. It would be naive to simply say

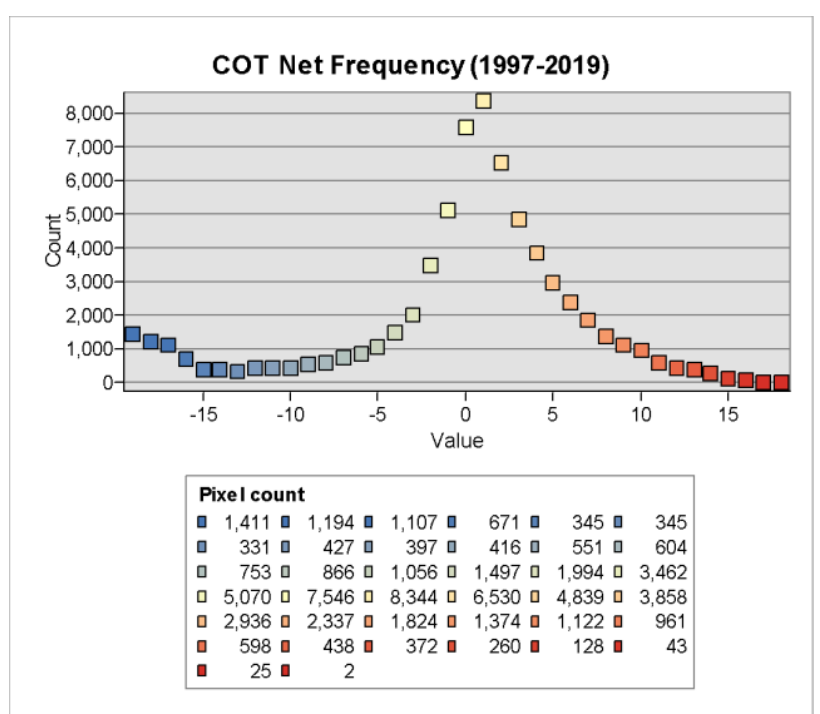

Figure 3. Grid cell (pixel) value vs count of output net frequency of cluster and outlier type (COT) in Metro Manila for 1997 to 2019.

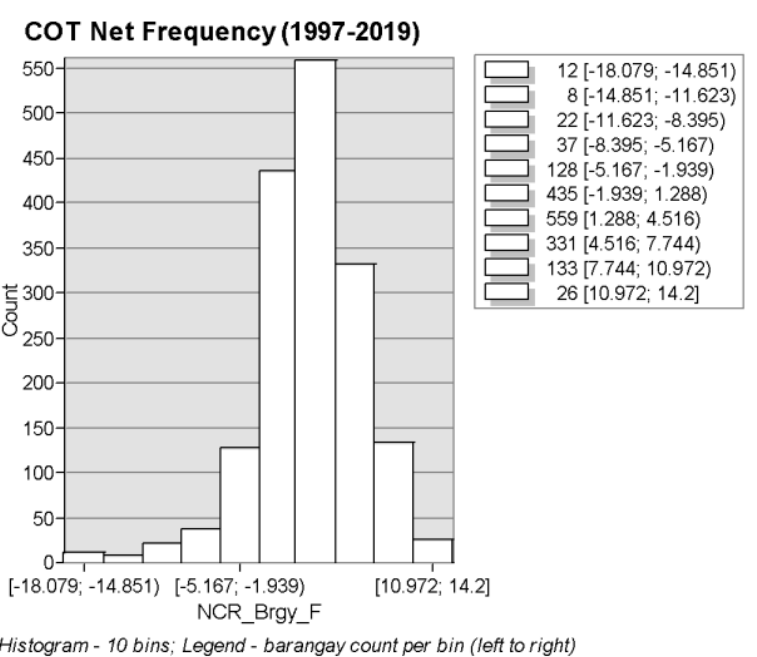

Figure 4. Histogram (10 bins) of output net frequency of cluster and outlier types (COT) in Metro Manila for 1997 to 2019.

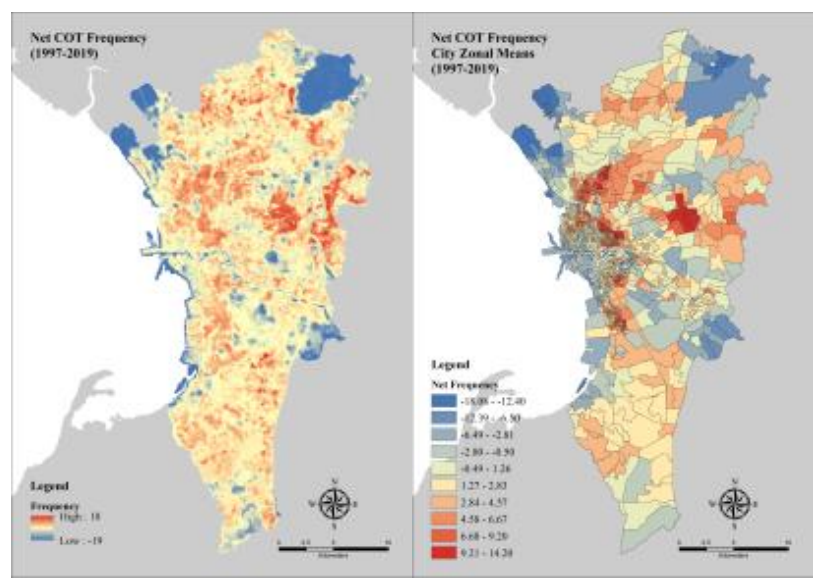

Figure 5. Net Cluster and Outlier Type (COT) Frequency maps of Metro Manila for years 1997 to 2019. (a) Raster (100-meter resolution), (b) City Zonal Means. 
that the establishment of urban green spaces within Metro Manila shall counter the effects of the UHI phenomenon. This is because in developing countries like the Philippines, there is an immense pressure for space, resources and development (Haq, 2011). However, emphasis on the roles of such spaces is significant. According to the World Health Organization, these kinds of spaces play a critical role in cooling cities, reducing health inequalities, and improving overall well-being. This is the goal of this study, to support the idea that urban green spaces can serve as measures to counter the adverse effects of worsening temperature conditions in consideration of the vulnerable population. These findings should solidify the idea of the role of urban cooling islands - areas that have lower temperature compared to its surrounding, especially in the case of Metro Manila (Lee et al., 2016).

Since this study mainly investigates surface temperature as the causal variable for how the IUHI's and anti-IUHI's are distributed in the study area, the effect of other variables is disregarded.

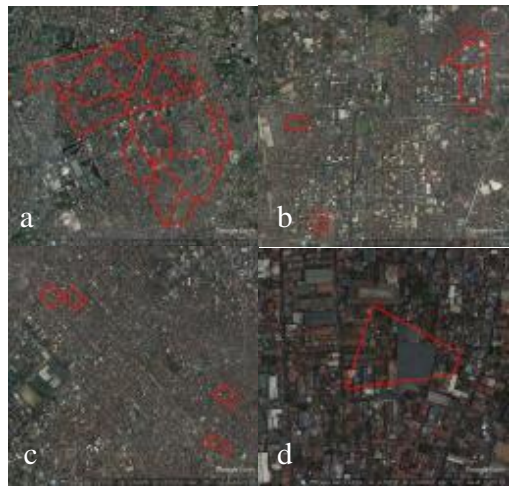

Figure 6. Intra-Urban Heat Islands (IUHI) in the barangays of (a) Quezon City, (b) Caloocan City, (c) Manila, and (d) Pasay City.

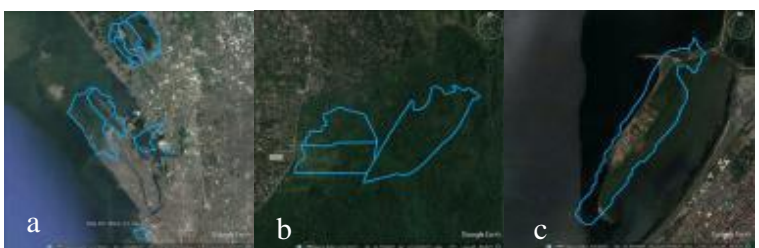

Figure 7. Anti-Intra-Urban Heat Islands (Anti-IUHI's) in the barangays of (a) Navotas, Malabon, and Valenzuela, (b) Caloocan City, and (c) Las Piñas.

\subsection{Trend Characterization}

\subsubsection{Spatio-Temporal Cluster Behaviour}

With the output cluster type change maps from 1997 to 2019 , nine different types of cluster behaviours were identified as mentioned previously. A graph showing the grid cell count per change type is shown on Figure 8. Evidently, the "Neutral (no change)" behavior is the most dominant. This can be attributed to the fact that the significance filter for the Univariate Local Moran's I function in GeoDa was raised to 0.001 which led to a stricter classification of COT's based on the input LST's. Additionally, based on the graph in Figure 8, the intensity of cluster type changes varies over time. It can also be said that the cluster type changes vary over space, except for some of the areas with grid cells classified into the "Coldspot (no change)" behavior. The reported spatial and temporal variations of the cluster type change phenomenon in the study area is summarized in Figure 8 and is portrayed in Figure 9. Temperature is known to be a non-stationary process. This means that the intensity should vary spatially and temporally. This also means that the temporal distribution of the identified cluster areas should also vary over time. However, patterns in the distribution and intensity of LST led to the emergence of IUHI's and anti-IUHI's which is suggestive of non-stationarity. Therefore, the existence of a possible underlying spatial or temporal characteristic causing the emergence of such patterns cannot be dismissed.

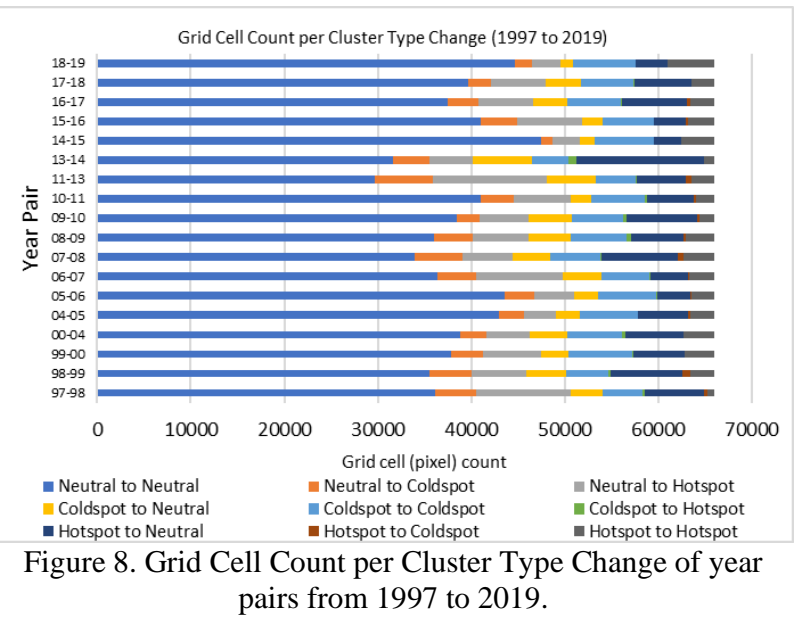

\subsubsection{Land Surface Temperature and Cluster Area Trend}

Mean surface temperatures of the whole study area, along with the mean cluster areas in $\mathrm{km}^{2}$ were recorded and plotted against time (Figure 10). Linear trendlines fit to the graph show increasing trends of the surface temperatures $\left(0.18\right.$ increase in ${ }^{\circ} \mathrm{C}$ per year), and the hotspot area $\left(0.03 \mathrm{~km}^{2}\right.$ per year $)$ and a decreasing trend for the coldspot area $\left(0.01 \mathrm{~km}^{2}\right.$ per year). The $\mathrm{r}$ squared value however denotes weak positive correlations 0.2 , $0.05,0.02$ respectively of the mean variable values to year. It should be noted however, that $\mathrm{r}$-squared is biased with regards to the number of inputs.

Noticeably, LST's peaked at years 1997, 2006, 2010, 2015 and 2018. Coincidentally, the years 1997, 2002, 2006, 2010, and 2015 were recorded as to have had El Niño episodes by the NOAA and the Australia Bureau of Meteorology. El Niño affects the weather in such a way that the tropical Pacific waters undergo warming affecting wind circulation patterns leaving the region unseasonably dry recurring at irregular intervals (NOAA, 2015; Kovats et al., 1999). The El Niño is a "warm event" and has an effect on the Asian monsoon and hurricane activity and in some cases is followed by a less pronounced La Niña (a "cold event"). The dips in LST's of the succeeding years after an El Niño episode as shown in Figure 10 is characteristic of the El Niño-La Niña relationship. Unfortunately, high LST's are just one of the El Niño phenomenon's effects. Warmer temperatures are linked and related to cause more destructive typhoons, widespread vectorborne diseases such as dengue (Kovats et al., 1999), water shortages such as in Cape Town, South Africa and in Botswana back in 2015, low electricity supply (hydropower) in Lusaka, Zambia in 2015 and widespread drought conditions in South Africa (Gannon et al., 2018) among many others. These are regardless of whether the areas are urban or rural. The El NiñoLa Niña relationship (peaks and dips) substantially characterizes the LST trends which succeedingly dictates the cluster area trend for the study area. It could then be suggested that climatological and meteorological phenomena significantly affects these trends. 


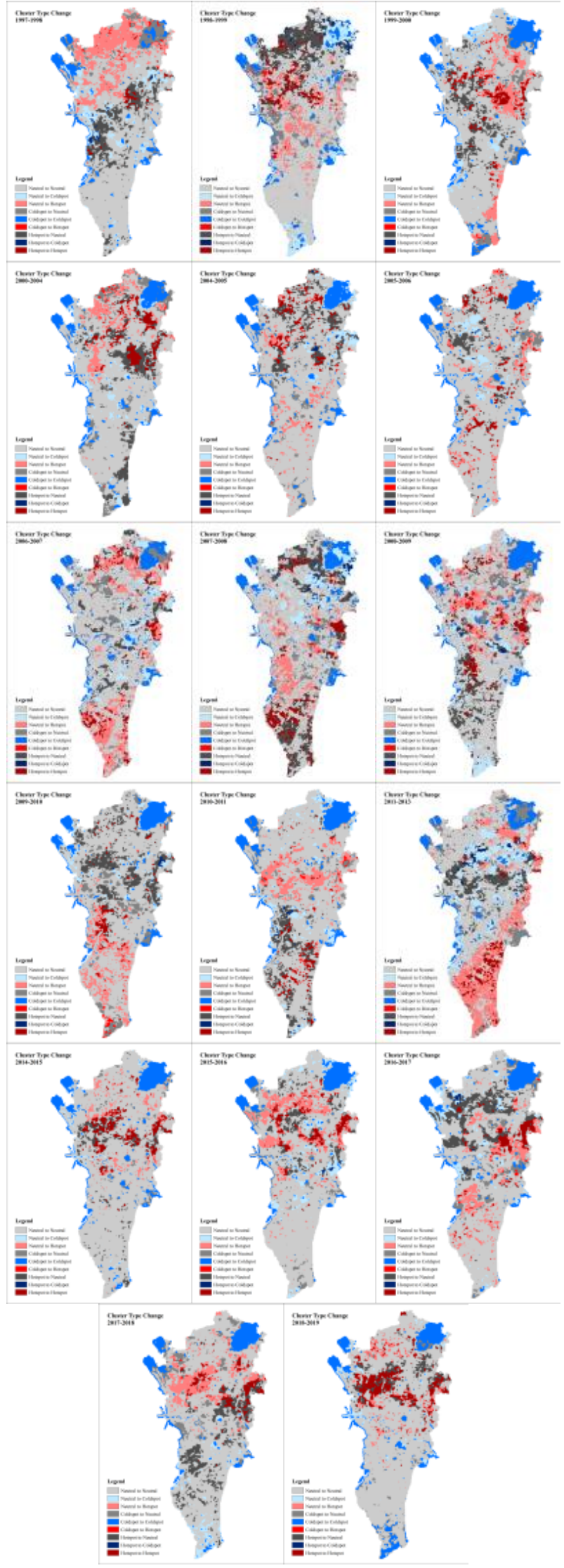

Figure 9. Cluster type change behaviors in Metro Manila per year pair (left to right, top to bottom: 1997-1998 to 2018-2019). neutral (no change), neutral to coldspot, neutral to hotspot, coldspot to neutral, coldspot (no change), coldspot to hotspot, hotspot to neutral, hotspot to coldspot, and hotspot (no change).

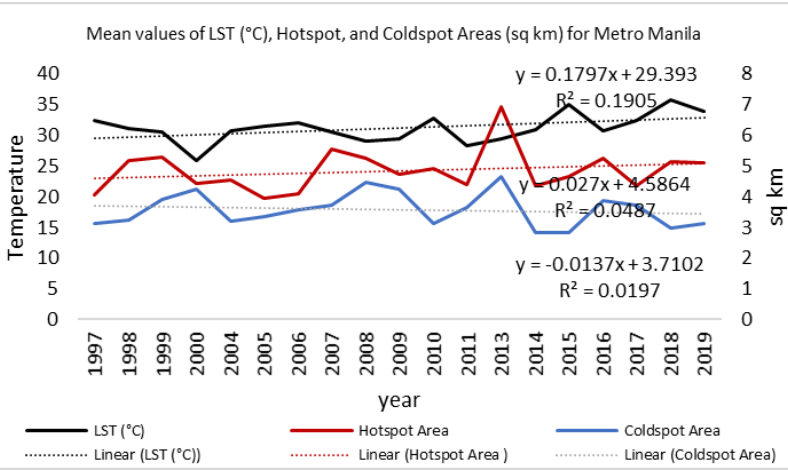

Figure 10. Mean values of LST $\left({ }^{\circ} \mathrm{C}\right)$, Hotspot, and Coldspot Areas $\left(\mathrm{km}^{2}\right)$ for Metro Manila.
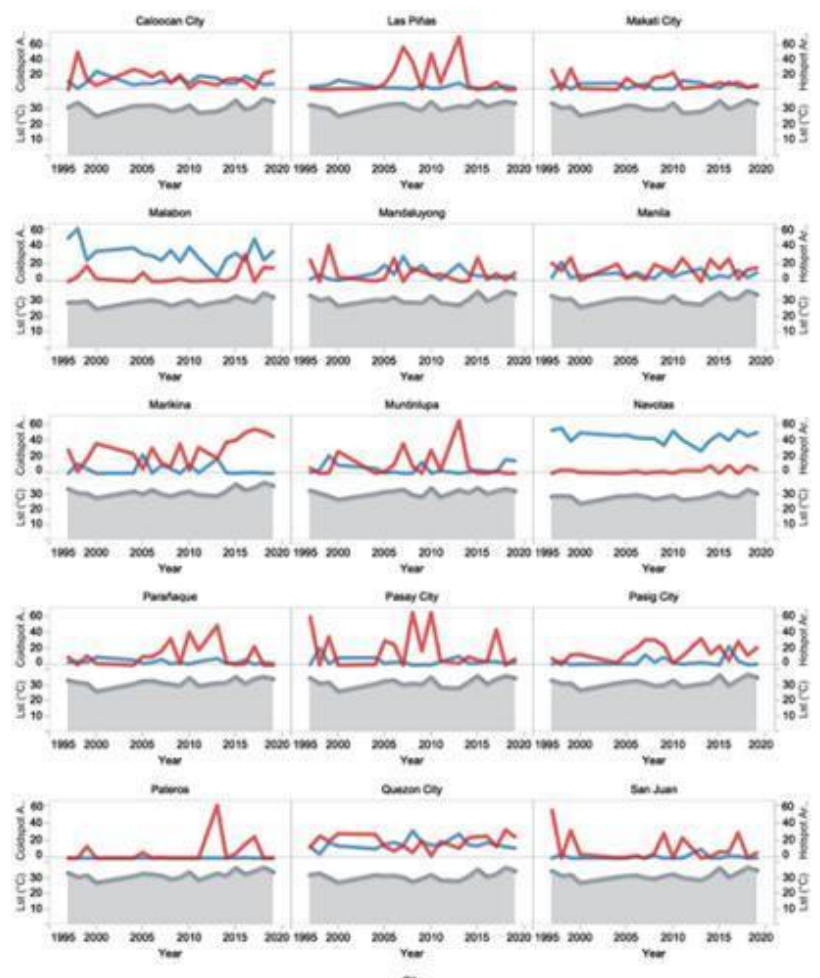

bil

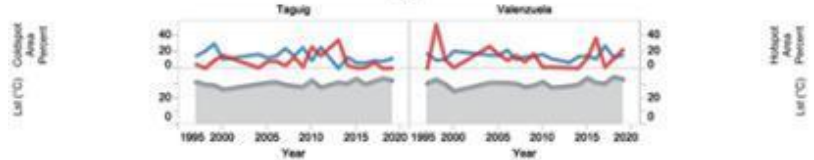

|1!

Figure 11. Time series plots of LST per city superimposed with cluster area percentages (cluster area divided by city area) for Metro Manila.

LST values and cluster area percentages were plotted against time. Figure 11 shows the annual variation of all three variables throughout the study period (1997-2019) as plotted per city of the study area. Area percentages were used since the use of $\mathrm{km}^{2}$ fail to capture the detail of the cluster area data especially for cities with small areas such as Pateros and San Juan. Noticeably, Malabon and Navotas appear to not conform to the trend of the cities of dominantly having a greater percentage of their area categorized as hotspots. This can be attributed to the fact that these cities enclose substantial extents of water bodies in their administrative boundary which was used as the spatial unit of analysis. It is worth noting also that the spikes in hotspot area percentages coincide with the pronounced El Niño episodes. Another substantial observation is how the hotspot area percentages peak where coldspot area percentages dip and vice- 


\begin{tabular}{|c|c|c|c|c|c|c|c|c|c|c|}
\hline \multirow{2}{*}{ City } & \multirow{2}{*}{$\begin{array}{l}\text { Area* } \\
\left(\mathrm{km}^{2}\right)\end{array}$} & \multicolumn{3}{|c|}{ LST trendlines } & \multicolumn{3}{|c|}{ Hotspot area $\left(\mathrm{km}^{2}\right)$ trendlines } & \multicolumn{3}{|c|}{ Coldspot Area $\left(\mathrm{km}^{2}\right)$ trendlines } \\
\hline & & Slope & Intercept & $\mathrm{p}$-value & Slope & Intercept & $\mathrm{p}$-value & Slope & Intercept & $\mathrm{p}$-value \\
\hline Caloocan & 46.98 & 0.121 & -211.285 & 0.208 & -0.147 & 303.569 & 0.455 & 0.014 & -23.782 & 0.872 \\
\hline Las Piñas & 33.19 & 0.159 & -286.682 & 0.041 & 0.096 & -187.173 & 0.717 & -0.058 & 118.325 & 0.091 \\
\hline Makati & 31.76 & 0.110 & -190.245 & 0.212 & -0.122 & 247.881 & 0.217 & 0.041 & -35.553 & 0.659 \\
\hline Malabon & 14.61 & 0.176 & -324.823 & 0.016 & 0.047 & -94.227 & 0.266 & 0.056 & 198.310 & 0.103 \\
\hline Mandaluyong & 10.95 & 0.130 & -229.335 & 0.163 & -0.052 & 106.075 & 0.236 & 0.028 & -3.158 & 0.941 \\
\hline Manila & 36.68 & 0.133 & 0.133 & 0.121 & -0.001 & 6.158 & 0.996 & 0.061 & 52.970 & 0.690 \\
\hline Marikina & 22.14 & 0.208 & -385.727 & 0.021 & 0.327 & -651.29 & 0.006 & 0.052 & 94.249 & 0.389 \\
\hline Muntinlupa & 38.52 & 0.126 & -222.049 & 0.091 & -0.016 & 35.803 & 0.947 & 0.091 & 8.487 & 0.972 \\
\hline Navotas & 7.87 & 0.128 & -228.166 & 0.046 & 0.015 & -29.894 & 0.051 & -0.017 & 37.598 & 0.381 \\
\hline Parañaque & 44.18 & 0.149 & -267.601 & 0.053 & 0.078 & -151.48 & 0.732 & -0.051 & 104.425 & 0.178 \\
\hline Pasay & 18.68 & 0.125 & -218.421 & 0.187 & -0.130 & 264.136 & 0.391 & -0.042 & 84.702 & 0.200 \\
\hline Pasig & 31.56 & 0.161 & -291.961 & 0.055 & 0.170 & -336.455 & 0.126 & 0.050 & -98.423 & 0.426 \\
\hline Pateros** & 1.96 & 0.183 & -335.302 & 0.024 & 0.010 & -20.332 & 0.312 & 0.001 & -0.166 & 0.298 \\
\hline Quezon & 148.00 & 0.134 & -237.579 & 0.131 & 0.233 & -441.054 & 0.585 & 0.222 & -423.010 & 0.459 \\
\hline San Juan & 5.78 & 0.132 & -234.049 & 0.129 & -0.035 & 71.839 & 0.248 & 0.002 & -3.050 & 0.760 \\
\hline Taguig & 27.66 & 0.158 & -285.855 & 0.029 & -0.017 & 37.326 & 0.851 & -0.159 & 323.903 & 0.024 \\
\hline Valenzuela & 37.25 & 0.122 & -214.106 & 0.167 & -0.095 & 195.626 & 0.609 & 0.007 & -8.837 & 0.909 \\
\hline
\end{tabular}

*computed from PhilGIS.org shapefile

**Pateros is a municipality

Table 2. Table summary of linear trendlines (slope, intercept, and p-value of the line) for each LST, hotspot area, and coldspot area time-series plots per city in Metro Manila.

versa which supports the idea of the inverse relationship between the two.

As a main aim of the study, linear trendlines were used to identify whether trends of the variables rise or fall. Table 2 summarizes the linear trendlines' slope, intercept, and the p-value per variable per city. Linear trend models were computed for coldspot area $\left(\mathrm{km}^{2}\right)$, hotspot area $\left(\mathrm{km}^{2}\right)$, and LST given year. Corresponding model formulas are shown on equations 9-11.

$$
\begin{aligned}
& \text { Coldspot area }\left(\mathrm{km}^{2}\right) * \text { City } *(\text { year }+ \text { intercept }) \\
& \text { Hotspot area }\left(\mathrm{km}^{2}\right) * \text { City } *(\text { year }+ \text { intercept }) \\
& \text { LST }\left({ }^{\circ} \mathrm{C}\right) * \text { City } *(\text { year }+ \text { intercept })
\end{aligned}
$$

The models may be significant at $\mathrm{p} \leq 0.05$ but $\mathrm{p}$-values (significance) of trendline models are less than 0.0001 . The number of modelled observations for all models is 323 with degrees of freedom equal to 34 and the residual degrees of freedom equal to 289 . Respective r-squared values per model are as follows: (1) 0.82 , (2) 0.62 , and (3) 0.25. Such r-squared values describe the models respectively as being substantial, moderate, and weak (Henseler et al., 2009). Standard errors of the models are $2.59,5.06$, and 2.33 respectively. The slopes denote the predicted increase or decrease in the values of the variables $\left({ }^{\circ} \mathrm{C}\right.$ for LST, and in $\mathrm{km}^{2}$ for the cluster areas) per increment in year. Four different types of trends were observed based on the equations of the linear-fit trendlines. First is a trend characterized by an increase in LST, a decrease in hotspot area but an increase in coldspot area. This may be contradictory, but this could mean that the low-range LST's increased collectively. Second is a trend characterized by increasing LST and decreasing cluster areas. The decrease can be attributed to the development of variance in the LST's which could have led to the decline of clusters of both high and low LST's. Third is a trend characterized by increasing LST and hotspot area, and a decreasing coldspot area. This is possibly due to a substantial increase in high-range LST's in the study area leading to larger clusters of high LST's. Last is a trend characterized by increasing LST and cluster areas. This is probably due to spatially consistent increase in LST or simply that the whole range of LST values increased as a collective leading to larger cluster areas.

\section{CONCLUSION AND RECOMMENDATIONS}

The use of the Univariate Local Moran's I along with remote sensing theory applications and GIS techniques in this study prove the existence of IUHI's within the UHI that is Metro Manila. The existence of IUHI's support the notion that the urban environmental condition in the study area is degrading. Clearly, this urban environmental degradation is further aggravated by the observed increasing trend in LST that is consistent for all cities in Metro Manila. Expected increases in hotspot areas and decreases in coldspot areas are just some of the repercussions of this trend in LST as can be observed from the results of this study. The located and identified clusters also show how dependent the intensity and distribution of LST is to the urban form - surface roughness, geometry and land use-land cover distribution. Although inconclusive, this sheds light on the importance of the presence of vegetative cover and water bodies in thermal environment of urban areas. This also sheds light on the underlying spatial and temporal characteristic of the study area which is the cause of the observed stationarity of temperature in the existence of the IUHI's and the anti-IUHI's. In general, it can be said that in this study, LST distribution and trends are influenced by urban form, land use and land cover distribution, and meteorological and climatological phenomena. This study supports the incorporation of the thermal environment properties in urban planning of the cities in order to address and mitigate the adverse effects of the UHI phenomenon.

It should be noted that this study investigated surface temperatures retrieved from satellite data. The data used came from the "tier 1" collection from Google Earth Engine which is considered as analysis-ready data. Satellite data with finer resolutions maybe able to yield results at a finer scale since the resolution of Landsat data particularly its thermal bands, is 100 meters and is resampled only to 30 . Other spatial units of analysis should be explored because larger units can lead to loss of spatial detail and finer units can lead to high variance. Trendlines that are more fit for the dataset should also be explored for further studies since annual LST's are not linearly increasing. Although linear trendlines served its purpose in this study in characterizing whether the trends are increasing or 
decreasing, it is in a way unyielding. Lastly, this is a univariate study of the LST in Metro Manila, but temperature is an anisotropic process. Therefore, future studies should consider a multivariate approach to better understand LST intensities and distribution and consequently, the distribution and the behaviours of clusters specifically IUHI's and anti-IUHI's through time.

\section{ACKNOWLEDGEMENTS}

The authors would like to acknowledge the Department of Science and Technology (DOST), and DOST Philippine Council for Industry, Energy, and Emerging Technology Research and Development (PCIEERD), Republic of the Philippines for funding and monitoring Project Number 4028, "Geospatial Assessment and Modelling of Urban Heat Islands in Philippine Cities" (Project GUHeat).

\section{REFERENCES}

Anselin, L. 1995. Local Indicators of Spatial Association - Lisa. Geographical Analysis 27 (2): 93-115. doi:10.1111/j.15384632.1995.tb00338.x.

Asian Development Bank. 2014. 2014 ANNUAL REPORT. Retrieved from:

https://www.adb.org/sites/default/files/institutional-

document/158032/adb-annual-report-2014.pdf

AskAboutIreland, the Cultural Heritage Project. n.d. The Built Environment. Retrieved from

http://www.askaboutireland.ie/enfo/irelands-environment/thebuilt-environment/

Bartkowiak, P., Osinska-Skotak, K. 2018. Application of geostatistical modelling to study the relationships between the surface urban heat island effect and land-cover using Landsat time series data. Retrieved from:

https://www.researchgate.net/publication/323965931

Bernales, A., Antolihao, J., Samonte, C., Campomanes, F., Rojas, R., dela Serna, A., Silapan, J. 2016. Modelling the Relationship Between Land Surface Temperature and Landscape Patterns of Land Use Land Cover Classification Using Multi Linear Regression Models. XXIII ISPRS Congress, 1-19 July 2016, Prague, Czech Republic.

Gannon, K., Curran, P., Conway, D. 2018. El Niño is bringing drought threats for business in Southern Africa. THOMSON REUTERS FOUNDATION NEWS. Retrieved from http://news.trust.org/item/20181207151249-tlmjv

Gorelick, N., Hancher, M., Dixon, M., Ilyushchnko, S., Thau, D., Moore, R. 2017. Google Earth Engine: Planetary-scale geospatial analysis for everyone. Remote Sensing of Environment (2016), http://dx.dci.org/10.106/j.rse.2017.06031

Haq, S. 2011. Urban Green Spaces and an Integrative Approach to Sustainable Environment".Journal of Environmental Protection. Vol. 2. pp.601-608

Henseler, J., Ringle, C., and Sinkovics, R. 2009. "The use of partial least squares path modeling in international marketing." Advances in International Marketing (AIM), 20, 277-320)
Howard, L. 1818. The Climate of London. W. Phillips, George Yard, Lombard Street.

Huang, J., H. Akbari, and H. Taha. 1990. The Wind-Shielding and Shading Effects of Trees on Residential Heating and Cooling Requirements. ASHRAE Winter Meeting, American Society of Heating, Refrigerating and Air-Conditioning Engineers. Atlanta, Georgia

Jeevalakshmi D., Narayana Reddy, S., Manikiam, B. 2017. Land Surface Temperature Retrieval from Landsat data using Emissivity Estimation. International Journal of Applied Engineering Research. Vol. 12, No. 20. 9679-9687. http://www.ripublication.com

Kovats, R., Bouma, M., Haines, A. 1999. El Niño and Health. Protection of the Human Environment: Task Force on Climate and Health Geneva. WHO/SDE/PHE/99.4.

Lee, D., Oh, K., Seo, J. 2016. An Anaysis of Urban Cooling Island (UCI) Effects by Water Spaces Applying UCI Indices. International Journal of Environmental Science and Development, Vol. 7, No. 11, November 2016.

Martin, P., Baudouin Y., \& Gachon, P. 2015. An Alternative Method to Characterize the Surface Urban Heat Island. International Journal of Biometeorology 59 (7): 849-61. doi:10.1007/s00484-014-0902-9.

Mojarro, J. 2017. Who 'killed' Metro Manila? RAPPLER. Retrieved from https://www.rappler.com/views/imho/191029metro-manila-decay-solution-urban-planning

Moloney, A. 2015. Which countries are worst affected by El Niño? World Economic Forum. Retrieved from https://www.weforum.org/agenda/2015/12/which-countries-areworst-affected-by-el-nino/

National Nutrition Council. 2015. Region NCR Profile. Retrieved from http://www.nnc.gov.ph/index.php/regionaloffices/national-capital-region/57-region-ncr-profile.html

Pahlavani, P., Karimi, A., Bigdeli, B. 2017. LAND USE ANALYSIS ON LAND SURFACE TEMPERATURE IN URBAN AREAS USING A GEOGRAPHICALLY WEIGHTED REGRESSION AND Landsat 8 IMAGERY, A CASE STUDY: TEHRAN, IRAN. Tehran's Joint ISPRS Conferences of GI Research, SMPR and EOEC 2017, 7-10 October 2017, Tehran, Iran.

Sobrino, J., Jiménez-Muñoz, J., Paolini, L., 2004. Land Surface Temperature retrieval from Landsat TM 5. Remote Sensing of Environment 90, pp. 434-440.

Stathopoulou, M., Cartalis, C. 2007. "Daytime urban heat islands from Landsat ETM+ and Corine land cover data: An application

World Health Organization. N.d. Urban Green Spaces.

Retrieved from https://www.who.int/sustainable-

development/cities/health-risks/urban-green-space/en/

Zheng, X., Zhao, K. 2010. A Method for Surface Roughness Parameter Estimation in Passive Microwave Remote Sensing. Chinese Geographical Science. Vol. 20 no. 4. Pp. 345-352. 